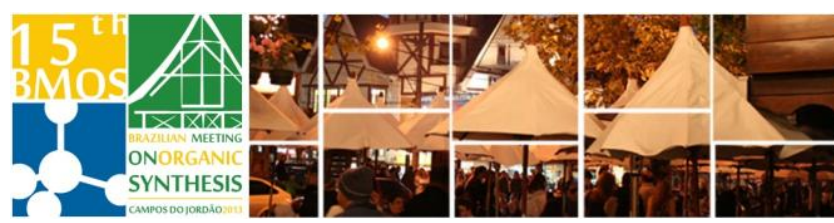

\title{
Cycloadducts Synthesis and Relative Stereochemistry Determined by NMR and DFT-GIAO calculations
}

\author{
Gabriela da C. Resende* and Elson S. de Alvarenga \\ LASA, Departamento de Química, Universidade Federal de Viçosa, UFV, Viçosa, MG, 36571-000 \\ *gabriela.resende@ufv.br
}

Keywords: butenolides, phthalides and Diels-Alder

\section{INTRODUCTION}

The isobenzofuran-1(3H)-ones (or phthalides) and dihydro, tetrahydro, and hexahydro derivatives are a group of secondary metabolites mostly produced by several genera of the family Apiaceae ${ }^{1}$. These bicyclic $\gamma$-lactones have been studied because of their wide range of bioactivities ${ }^{2}$.In our work, the Diels-Alder reaction was chosen as the key step to obtain tetrahydroisobenzofuran-1(3H)-ones derivatives from $\mathrm{C}-5$ substituted butenolides, since $\alpha, \beta$-unsaturated $\gamma$-lactones act as excellent dienophiles in cycloaddition reactions with dienes ${ }^{3}$.

\section{RESULTS AND DISCUSSION}

For the reaction between generic lactone $\mathbf{1}$ and cyclopentadiene (Cp) only the adducts anti-endo $\mathbf{2 a}$ and anti-exo $3 \mathbf{a}$, should be formed (Scheme 1$)^{4}$. However, the adduct syn-endo $\mathbf{2 b}$ was also isolated for lactone 1c (Table 1).

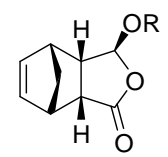

(2a) anti-endo

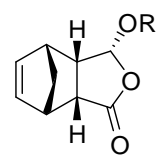

(2b) syn-endo

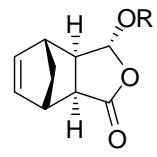

(3a) anti-exo

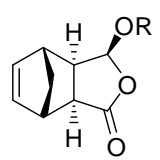

(3b) syn-exo
Scheme 1. Possible adducts (enantiomers are not represented) for the DA reaction between C-5 substituted butenolides and cyclopentadiene.

Table 1. Reactions of lactones 1a-c with cyclopentadiene

\begin{tabular}{|c|c|c|c|c|c|}
\hline \multirow{2}{*}{$\begin{array}{c}\text { Lactone: } \\
\text {-OR } \\
\text { group }\end{array}$} & \multirow{2}{*}{$\begin{array}{c}\text { Reaction } \\
\text { conditions }^{\mathrm{a}}\end{array}$} & \multirow{2}{*}{$\begin{array}{c}\text { Yield } \\
(\%)^{\mathrm{b}}\end{array}$} & $\begin{array}{c}\text { Anti- } \\
\text { endo } \\
\text { 2a }\end{array}$ & $\begin{array}{c}\text { Anti- } \\
\text { exo } \\
\text { 3a }\end{array}$ & $\begin{array}{c}\text { Syn- } \\
\text { endo } \\
\text { 2b }\end{array}$ \\
\hline 1a: $\mathrm{OAc}$ & $\mathrm{A}$ & 98 & 95 & 5 & - \\
\hline 1b: $\mathrm{OH}$ & $\mathrm{B}$ & 96 & 97 & 3 & - \\
\hline 1c: $\mathrm{OiPr}$ & $\mathrm{C}$ & 91 & 83 & 9 & 8 \\
\hline
\end{tabular}

${ }^{a}$ A: 3.4 eq.of Cp, 20h; B: 2.4 eq., DCM, 20h; C: 4.3 eq., 96h.

${ }^{\mathrm{b}}$ Combined yield of pure products after chromatography.

(\%) Determined by CG/MS.
The relative stereochemistry of the products was established by NMR experiments (Fig.1) and DFT calculations. In adducts from lactone 1c, for example, the COSY presented a cross correlation signal of $\mathrm{H}-13^{\prime}$ with $\mathrm{H}-3$ and $\mathrm{H}-4$ for the endo adducts. Moreover, a NOE enhancement of $5 \%$ was observed on $\mathrm{H} 4$ from $\mathrm{H} 13$ ' on syn-endo and antiendo isomers, while this effect has not been observed in anti-exo. A NOE enhancement of 4,0\% was observed on $\mathrm{H}-9$ by irradiating $\mathrm{H}-4$ on anti-exo.

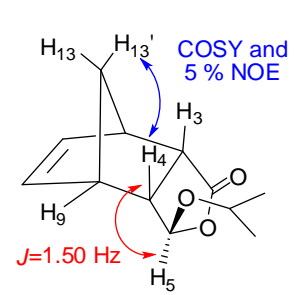

(2ac) anti-endo

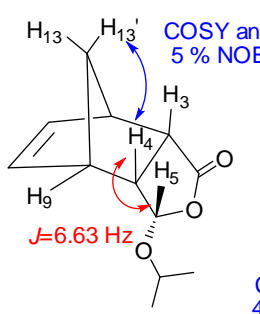

(2bc) syn-endo

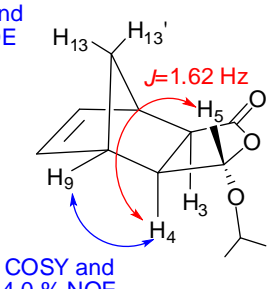

(3ac) anti-exo
Figure 1. Representation of positive NOE interactions, COSY correlations and coupling constants for butenolide 1c cycloadducts.

On the ${ }^{1} \mathrm{H}$ NMR spectra were observed coupling constants between $\mathrm{H}-4$ and $\mathrm{H}-5$ of $1.62 \mathrm{~Hz}$ for antiexo adduct and $1.50 \mathrm{~Hz}$ for anti-endo adduct whereas for the syn isomer, this constant is $6.63 \mathrm{~Hz}$. The unequivocally assignment of all ${ }^{1} \mathrm{H}$ and ${ }^{13} \mathrm{C}$ signals were possible with the assistance of HETCOR experiments and DFT-GIAO calculations.

\section{CONCLUSION}

The DA reactions with $\mathrm{C}-5$ substituted $\alpha, \beta$ unsaturated $\gamma$-lactones and cyclopentadiene was successfully employed to synthesize seven analogues of tetrahydroisobenzofuran-1(3H)-ones which were structurally elucidated by NMR techniques and DFT calculations.

\section{ACKNOWLEDGEMENTS}

We thanks to UFV, CAPES, FAPEMIG and CNPq

\section{REFERENCES}

${ }^{1}$ Beck, J. J.; Chou, S. C. J. Nat. Prod.2007, 108, 891.

${ }^{2}$ Chamoli,T.; Rawat, M. S. M. Med Chem. Res. 2013, 22, 453.

${ }^{3}$ Benmeddah, A.; Mekelleche, S. M.; Benchouk, W.; Kara B. M.;

Villemin, D. J. Mol.Struct.(Theochem).2007,821, 42.

${ }^{4}$ Ruano, J. L. G.; Bercial, F.; Fraile, A.; Castro, A. M. M.; Martín,

M. R. Tetrahedron: Asymmetry.2000, 11, 4737. 